\title{
Musictherapy joined to Gardentherapy, Environmental Education and Experimental Pedagogy for the Disability
}

\author{
Adriana De Serio ${ }^{1}$, Donato Forenza ${ }^{2}$ \\ ${ }^{1}$ Music Conservatory, ${ }^{2}$ University, Bari (Italy)
}

\begin{abstract}
The people and the common imagination feel the charm of the magic and the dimensional versatility of beautiful gardens and forest zones, fascinating houses inside some places that inspire the people with an aesthetic pleasure and allegorical meanings of high spirituality and symbolize the continuity of the traditions, the genius loci. In this experimental research study the Authors attach a strategic importance to the environment resources and sonorous-musical energy joined to some integrated therapies for patients suffering from disabilities. The authors introduce a new methodology of Musictherapy joined to Gardentherapy and Environmental Education and Experimental Pedagogy for the Physical Disability (MusGarEnEdExPe) they created. The MusGar-EnEdExPe can help the musictherapist in team-work with the pedagogist, the gardentherapist and the environmental specialists on with some safe hooks to promote the patient's motivation to learn to face the physical disability and to overcome distress, psychological weakness and social seclusion. The aims of the MusGar-EnEdExPe are to strengthen the patient's identity and the mental and physical abilities and resilience to face the congenital / acquired disability. The patients (91\%) show the musictherapy and the gardentherapy inside GreenZones and ecosystems meet with their approval. After the musictherapy treatment the pedagogist facilitates the group narration process. In this way it is possible to reduce the patient's stress and every trauma can be processed. There are numerous convergences between mind and music that are closely and mutually connected. Sound and music energy can promote a regressive sphere and an unexpected internal thought cohesion. The MusGarEnEdExPe promotes patient's psychophysical activation, better mood/affective-tone and relationships and significantly contributes to improve the life quality.
\end{abstract}

\section{Introduction}

In this experimental research study and work the Authors attach a strategic importance to the environment resources and sonorous-musical energy

joined to some integrated therapies addressed to patients suffering from disabilities.

The people and the common imagination feel the charm of the magic and the dimensional versatility of beautiful gardens and forest zones, fascinating houses inside some places that present the people with an aesthetic pleasure and allegorical meanings of high spirituality and symbolize the continuity of the traditions, the genius loci.

The Authors introduce a new methodology of Musictherapy joined to Gardentherapy and Environmental Education and Experimental Pedagogy for the Physical Disability (MusGarEnEdExPe).

The historical analysis of the complex socioenvironmental phenomenologies highlights the remarkable incidence of the contribution of musical communication methodologies and the musictherapeutic values, with reference to the structural architecture of civilizations and cultures of the people.

The music is a language. And the language, as a semiological system defining contents and semanticphonetic data, makes the communication (verbal and non-verbal) possible, abounding in information and in affectivity too, expression of emotions.

The verb "to communicate" has a double (Greek and Latin) etymology that gives rise to the meaning and the dynamic and hermeneutic dimension, within a systemic ecological perspective, supporting the self-expression and the emotions, to meet the different world of other people, inside a relation process that gives rise to self-knowledge and selfawareness.

The communication promotes the sociality.

The music is a genetic, non-verbal language, based on the sounds, that are pre-verbal, symbolic and metalinguistic elements.

Therefore the music is characterized by intrinsic communicative purposes and offers considerable socializing opportunities, fully interpreting the human emotional experience.

The importance of the communicative and emotional effects of the music with reference to the psychogenetic, ontogenetic, anthropological and neurophysiological structure has been studied and proved since the pre-natal period. 
The rhythm-sound-movement stimulates the somatic and psychic behaviour of the fetus, and the bio-psychic exchanges between mother and child, in the intrauterine life and in the early months of life; after the birth, moreover, it becomes a psychicaudio-phonic-kinetic agent in order to program the early forms of organization of the space, the newborn's perception of his body, that has a very close bond with the mother at first, and later the separation of the bodily self from the maternal self.

The mother body, with the heart, blood, breath, womb, voice pulsations, sets up the first sound score, and an orchestra, involved in modeling the identity of the unborn child and the individual-bodyinstrument that was born; in adulthood, this dyadic experience can arise again and he can approach biosemiotics and can develop emotional feelings and empathy that harmonize and syntonize the intercorporeal and sonorous-emotional dialogue.

Since very remote times, great importance has been attached to the music in relation to the emotional expression and communication as well as therapy.

The most ancient traditions of the peoples describe the spread of the cult of the sound and its power of transformation and regeneration. These potentialities weave the sound of the voice and the daily expression of the verbal universe: the world is continually recreated by the sounds of the voice.

The verbal language and the word are modeled according to codes and traditions and constitute only an element of the communication.

The rational thinking, the linear and causal logic, the filters of ideas-memories and ideas-evaluations can set the totality of vital experiences within the lines of logical structures and the boundaries of verbal terms.

For over half a century, the international literature carries the results of analytical scientific studies of the social behaviours and the man / sound relationship and the epistemological foundations.

In this way the valorization of the resources of the (non-verbal) musical communication and the musictherapy increases, in order to pursue educational, preventive, rehabilitative and therapeutic goals.

The musictherapy uses interventions led by the non-verbal communication of which the musical language is part, incorporating a complex sonorous universe: audible frequencies (between 16 and 16.000 - $20.000 \mathrm{~Hz}$ ), not audible but perceptible frequencies by means of the sense-organs, tactile pressure, rhythm and movement, noise, in a dynamic and varied continuity.

The sound is a physical event too, produced by vibrations of elastic bodies that propagate in the air by means of periodic waves of condensation and molecular rarefaction. The transmission of the sound is inherent in the transmission not of matter, but of energy, interacting with the environment.

The musictherapy is the clinical and evidencebased use of music interventions to accomplish individualized goals within a therapeutic relationship.

The musictherapy is addressed to physical, emotional, cognitive and social needs of the individuals and provides avenues for a better communication and productive social relations by treatments including music creation and listening and singing production.

Therefore the Authors created an innovating definition of musictherapy: "The musictherapy is a multidisciplinary science that contributes to the wellbeing and the psycho-physical integration of the person within the system of social relationships, by the creative use of the Sonorous-Musical-Energy (ESM ) and the therapist himself" [2]

The research in musictherapy supports its effectiveness in many areas such as the psychophysical rehabilitation, increasing patient's motivation to become engaged in the treatment and providing an emotional support for the patients and their families and an outlet for the expression of their feelings.

Surprisingly, the life rhythm and the harmony of small towns benefit by the excitant views of nice places.

From the Middle Ages to the Renaissance all over the world the people like the beauty. They look for emotions inside some natural and uncontaminated places that are the UNESCO heritage very often [16 - 18].

The colourful coasts preserve fascinating images, the ancient buildings tell stories of legendary battles.

Reminiscences of the Mediterranean sea, sometimes natural fortifications, territorial attractions structuralize the semiotics of the sublime, including the historical walls of the towns, the beaches, the Cathedrals on the shores of the sea, the blades that meet the coasts and mark the singleness of incontamined settings, extraordinary landscapes, phantasmagoric environmental scenes.

As regards the gardentherapy, already in 1778 the curative effects of the cultivation of the land on patients with mental disorders were well-known.

In 1879 there was the first case of a greenhouse built in the United States, in Pennsylvania, just for the care of hospitalized patients suffering from mental diseases. The same therapy was applied to relieve the war veterans.

The gardentherapy decreases physical and mental tensions (about $70 \%$ ), reducing anxiety and stress, facilitating the connections between the cerebral 
hemispheres, thus also improving the mental and intellectual performances.

The gardentherapy shows the benefits even on diseases such as autism and schizophrenia.

The psychological well-being that comes from the contact with the plants directly affects the essential functions of the body, improving the circulation, regulating the blood pressure and reducing the cholesterol levels.

The gardentherapy can provide for healing gardens, therapeutic gardens, garden-food, horticultural therapy, and in this way can contribute to improve self-confidence and mood, to relieve depression, to increase motor skills and problemsolving skills, to promote social interactions and relationships [13].

The experimental pedagogy explores new ways of education and exceeds all unilateral and onedimensional pedagogical theories.

The birth of the experimental pedagogy is due to the adoption of an empirical experimental approach based on the use of an inductive method, in order to study the events inside the various educational activities.

The experimental pedagogy regards researches founded on a method of scientific work that allows you to progress with the knowledge critically.

The experimental pedagogy enables the teacher to learn, to explore and to apply new educational horizons with the patients too, that benefit by these scientific findings.

The culture of the landscape protection needs to be spread over the territory of the planet. Therefore, a widespread campaign of culture of environment protection needs to be carried out within public and private institutions, schools, universities, parishes, municipalities, mountain communities.

A suitable educational and science-based plan needs to be carried out simultaneously by specialists through audiovisual and advanced technology craft to increase the environment and landscape and forest culture [19].

The scientific information actions need to be distinguished from the training and other measures aimed at prevention and protection, according to the cultural level of the users. The latter can apply the acquired knowledge as part of the sphere of activity (work or study) in order to establish processes for the promotion of the landscape and historical and architectural heritage.

The Authors point out the scientific literature deals with the landscape art, ancient olive trees, wide vineyards, oenological and gastronomic values, and woods that evoke purity, as symbolic references joined in the whole of the nature, that is the primitive mother related to the myths.
Dynamic architectural systems and rural agricultural settlements with typical farms draw a continuance of various chromatic configurations and extraordinary skylines of cities together with the multiform values of the mystery of the castles.

From immemorial time the myths attract artists and creative people from different cultural and scientific areas all over the planet.

Often the landscapes are the principal elements and the fundamental protagonists of beautiful pictures that portray unforgettable memories and enhance studies and researches and become sources of indescribable enthusiasm, emotions and psychophysical harmony.

Elements of magnificence feed the creation of parks and gardens.

Inside other wonderful ecological textures the natural resources and the order of plants and trees awaken the harmony of the rhythms and the poetry of the beauty of the inexhaustible composition and combination of the vegetation and the historical monuments.

In Italy the mosaic of landscapes is rich in biodiversity and multifarious environments and a territory endowed with unique peculiarities [20 - 21].

The Italy is characterized by a mountainous and hilly territory for the most part (about 82\%). Woods and forests are present in a smaller part (more than $34.7 \%$ ).

Sometimes the defence of the beauty of rural landscapes is joined in the absence of aesthetic ambitions.

In some cases the technical infrastructures created with strict observance of the landscape design can contribute to revalue the characteristics of the natural beauties allowing the use of inaccessible scenarios.

The musictherapy methodologies joined to the gardentherapy and the environmental education carried out by some experimental pedagogic methods give considerable opportunities for the psychophysical rehabilitation and an improvement in the cognitive process in order to promote the patient's self-determination, self-help and selfgovernment [9].

\section{Aims}

The methodology of the MusGar-EnEdExPe can help the professionals as the musictherapists joined to the pedagogists, the gardentherapists and the environmental specialists on with some safe hooks to promote the patient's motivation to learn to face the physical disability and to overcome the distress and the psychological weakness and the social seclusion [3]. 
Therefore, the aims of the MusGar-EnEdExPe are to strengthen the patient's identity and the mental and physical abilities and resilience to face the congenital /acquired disability [4].

\section{Methodological Systems}

\subsection{Structure of the methodology}

In this research work the Authors create several methodological algorhythms that give rise to thematic matters in relation to the different temporal stages.

The MusGar-EnEdExPe is carried out by an integrated therapeutic plan and in different spaces. inside:

The musictherapy treatments (MT) take place

- closed spaces as residential therapeutic centres for children, adult and old people (A1); nursing home (A2); hospital (A3);

- open spaces provided with Green Zones.

Then the methodology of the MusGar-EnEdExPe is carried out in Green Zones (GrZy) and in various ecosystems of the environment GrZy.

The field of variability is: $y=1,2, \ldots, 9$.

Therefore:

- GrZ1: urban green spaces, peri-urban green spaces, public green spaces, urban garden-food;

- GrZ2: natural rural zones, rural green spaces;

- GrZ3: designed gardens, designed green spaces;

- GrZ4: cultivated woods, natural woods;

- GrZ5: agricultural farm-house, country-house;

- GrZ6: natural parks, polichromatic forests;

- GrZ7: parks of hospital, public spaces close to the nursing home, public spaces close to residential therapeutic centres for children, for adult people, public spaces close to residential geriatrics centres;

- GrZ8: botanical gardens, garden-food;

- GrZ9: gardens close to the schools, vegetable gardens close to the schools, garden-food.

3.1.1. System Exemplification. The Authors point out a remarkable example of Biodiversity inside some GrZy in the Apulia region (Italy) that extends in the Mediterranean environment.

These zones show important environments and landscapes and are worth mentioning.

In the Apulia region the presence of oaks is considerable and all of these oaks are surveyed in the Italian nation: turkey-oak (Quercus cerris L.), holmoak (Quercus ilex L.), oak (Quercus pubescens Willd., Quercus petraea Lieb.), cork-oak (Quercus suber L.), fragno (Quercus Trojan Webb.), valloneaoak (Quercus macrolepis K.), thorny-oak (Quercus coccifera L.), English-oak (Quercus robur L.) and farnetto (Quercus frainetto T.).
In the Apulian region the landscape of the Gargano promontory is characterized by the National Park and the Umbra Forest. This territory is rich in beautiful specimens of beech (Fagus sylvatica).

The multiform coastal strips of the Apulia region and the blades are the destination of ecological routes.

There are the Aleppo pine (Pinus halepensis Mill.) and the domestic pine (Pinus pinea L.); for the most part some woods of Aleppo pine are natural forests.

The landscape is equipped with Mediterranean bush, that often takes the place of degraded forests and includes small trees, shrubs and aromatic bushes.

Among the many species mostly there are phillyrea, mastic, arbutus, myrtle, buckthorn, juniper, viburnum, wild olive trees and heather. Other species of deciduous and coniferous woods are present in the Apulia region to a smaller extent and generally affiliate to some main species: hornbeam, alder, elm, maple, flowering ash, hackberry, ash, lime, cypress, juniper, Aleppo pine [18].

In the Apulia region the vallonea oak and the fragno are some examples of endemic species and among the most frequent native species.

\subsection{Articulation of the methodology}

The musictherapy methodology is articulated according to some methodological steps.

Among the basic methodological elements of a musictherapy treatment there is the "good emotional distance" that must characterize every step and must always be present.

The "good emotional distance" could represent the ethical goal of the musictherapist, allowing him: - to prove flexible, welcoming and creative towards the subject / patient; - to be at the same time "inside and outside" the musictherapy setting, to organize and to manage it creatively, to read and to interpret and to lay it open to critical review of the musictherapeutic intervention and new and flexible strategies according to the evolution of the patient's clinical picture; - to activate a double-vision and to be aware of what is "given" by the real and what is "created" by the power of the mind in front of the observation of the real; - to know how to put one's theories and one's experience in brackets temporarily, to suspend any judgment, to participate without memory and desire, to grasp beyond what can be visible, to vibrate in resonance with what is "unseen".

Creativity for the musictherapist is to stretch one's ear, not only to establish the communication through a verbal semantic codification, but to prepare oneself for a perceptive action of fusion, 
communion, emotional sharing between one's own receiving skin and the issuing sonorous skin.

The creativity is required to carry out the bodyskin tactics and a deeper understanding of the verbal and non-verbal communication, that must be perceived not only as a more or less structuralized set of spoken or unspoken words, but as a sonorous skin, which allows the musictherapist to become aware of the signs, the scars, the salient features of a plot of unconsciously spoken life.

In order to listen to someone and to understand the non-verbal voice too the musictherapist must have an open mind on the biopsychic exchanges and must pay a great deal of attention to what the subject/patient does not say, whether he's able or unable to speak, the unconscious plot that makes his body a place of relationship and communication, an active plot that reactualizes his whole history through the subject's "word".

The musictherapy involves a rehabilitation training that is linked up with the mobilization of creative resources characteristic of the subject/patient; just these resources become a tool to achieve the outcome.

Only in this way it's possible to carry out a multidimensional assessment that takes the bodily, emotional, behavioural and relational aspects into account, and that makes the rehabilitation process suitable for each individual.

In musictherapy another important methodological element is the empathy that is the ability to guess and to perceive and to share the thoughts and feelings of another person.

The empathy is fundamental to establish channels of communication and positive relationships.

By the empathy the musictherapist can experience the patient's points of view and emotions through words and body language too as if they were your own and makes him feel heard.

The musictherapist-patient connection can further consolidate if the musictherapist assumes the cognitive state of the patient and sees a problem through his eyes.

By the empathy the musictherapist can sense other people's emotions and can imagine what someone else might be thinking or feeling.

In this way he can be focused on the patient's needs, as long as the musictherapist preserves his individuality and personality creating healthy boundaries in all relationships.

The musictherapy treatment is articulated according to the following steps.

- Sonorous-Musical Anamnesis of Patient (PSMA) and his Family (FSMA) in order to draw up the Musictherapy Assessment Document (MAD).
The PSMA and the FSMA are made from eighteen items that the patient and his family can understand easily. These items analyse the patient's family structure and sonorous-musical history stimulating his bodily-sonorous-musical memories also related to his fetal life and childbirth.

Therefore the MAD documents the non-verbal history of the patient. So the musictherapist can formulate some hypotheses in relation to the patient's sonorous identity in such a way as to make easier the management of the communication channels.

The sonorous identity characterizes each human being and is the sonorous form of the life experience and emotional-affective relationships and cognitive processes joined in the individual structure and consolidated both on the basis of the genetic heritage and environmental influences.

The MAD points out the musical habits of the patient and then let the musictherapist play timbres and music too that the patient knows.

In this way the musictherapist creates a continuity within the patient's life experience. Moreover, the MAD allows the musictherapist to establish a dialectical, informative, motivating and cooperative relationship with the patient's family (or caregiver) regarding methods and objectives of the musictherapeutic plan.

In hospital too the MAD is an efficient tool according to integrated collaboration strategies between musictherapist and medical team, in order to set up a context that is not only containing but also supporting the relational dimension.

In this way, each member of the interdisciplinary teamwork (specialist doctor, musictherapist, nurse, etc.) who is in charge of the patient can work at the set therapeutic and musictherapeutic goals.

The theoretical presuppositions of this organizational method are founded in the Theory of the Systems and in the Cybernetics of second level applied to social systems. According to this Cybernetics the social, physical and biological systems abide by the same laws (through communication and self-regulation processes based on the feedback).

Therefore, a system is settled when its components are bound by reciprocal and specific functional relationships.

The relationship modalities are essential for a system to be able to perform its functions and to respond through its own self-organized internal coherence to the changing and often unpredictable requests of the context in which the system is placed.

As regards a musictherapy treatment, it is further necessary that the organizational methods are such as to constitute a system that is able to empathize with 
the needs of the users and also to carry out a propulsive function through the creation of favorable conditions for the realization of new learnings and therefore for the psycho-physical growth of the users.

The MAD is important too in the context of the musictherapeutic plan for the family.

- Some Patient Observation Sessions (POS);

- Recorded / live Sonorous - Rhythmical Musical - Energy (SRME);

- Production of SRME and Bodily Environmental Rhythmical Sonorous Vocal Energy (BERSVE) through recorded classical music and modern songs the patient listens to;

- Production of Sonorous Environmental Energy (SEE) and Motor / Visual / Olfactory / Taste / Tactile Energy through environmental and landscape sounds (receptive musictherapy);

- Bodily Environmental Rhythmical Sonorous Vocal Energy (BERSVE) production by the musictherapist and the patients (active musictherapy).

The interactive systemic approach to the patientmusic bioecosystem involves a codification of (SRME)k choices, where $\mathrm{k}=1,2, \ldots, \mathrm{n} ; \mathrm{n}$ is the number of the musical pieces of the SRME production.

It must be borne in mind the importance of the musical biodiversity the musictherapist must contribute to produce inside the setting according to the biopsychic rhythm and the dynamic and agogic qualities of the feedback and the neurovegetative feedback too of the patient.

- Production of SRME by the use of Conventional and Non Conventional Sonorous Musical Instruments (cSMI and ncSMI) and some SMI made by the Author/musictherapist from salvage (SSMI), domestic articles and some foods (Edible SMI: ESMI) [7], [10],[11].

Edible Sonorous-Musical Instruments (ESMI): a roll empty of his crumb and stuffed with rice, or dough, and wrapped in tinfoil; tubular homemade pasta (as flute) or stuffed with legumes (as rainpipe); empty and stuffed egg with what the patient likes; empty capsicum of his seeds and stuffed with maize, or little pieces of parmesan, and then closed with sewing thread; empty pumpkin stuffed with croutons or pieces of candied oranges, or other foods; candied involucres of orange and mandarin stuffed with puffed rice; empty cream puff stuffed with pieces of chocolate, or peanuts, or almonds.

The use of the Sonorous-Musical Instruments needs an easy manipulation and a classification too for: historical, social, cultural, symbolical functions; way to produce the sound and to use; sonorousmusical features.
- Use of the musictherapist's voice and canto; use of the voice of the patient's relatives and friends (Sonorous-Vocal Energy: SVcE) [5].

Fundamental methodological elements of the BERSVE production are the sonorous-musical parameters of the SRME (sound, timbre, intensity, pitch, duration, rhythm, melody, harmony, form, fluctuations in velocity, dynamics, pulsation, phrasing, silence).

Each of the musical parameters is characterized by a peculiar energy value, and therefore should be monitored for each (SRME)k by the Imberty indexes too (general dynamism, dissimilarity of the elements, formal complexity) [14].

The Index of general dynamism is defined in this way:

$\mathrm{D}=\mathrm{V}$ x I (where: $\mathrm{D}=$ general dynamism; $\mathrm{V}=$ speed; $\mathrm{I}=$ subjective intensity).

The Index of dissimilarity of the elements is evaluated through the mean variation in intensity (intensity of every note separately produced in a time interval, the sum of the intensity of such notes inside the whole piece of music, the intensity average with reference to every played note and the mean variation in the musical piece), and the mean variation in duration (values of the relationships among the durations of the musical figures inside the same musical piece. The most frequent value is zero. Ex.: crotchet $=0$, minim $=2$, etc.)

The index of formal complexity is defined by: $\mathrm{C}=(\mathrm{Hm} \times \mathrm{t})+(\mathrm{el} \mathrm{x} e \mathrm{R})$, where: $\mathrm{C}=$ formal complexity; $\mathrm{Hm}=$ melodic entropy; $\mathrm{t}=$ duration of the metric interval; el = mean variation in intensity; $\mathrm{eR}=$ mean variation in duration .

The active musictherapy is carried out in several stages.

- Synchronization. The musictherapist meets the patient's bodily-sonorous (instrumental and vocal) musical activity through his instrumental/vocal improvisation [15]. The movement of the patient's hand/arms, hearing and more sensorial perceptions and speech are involved.

- Musical dialogue/game between the musictherapist and the patient in order to achieve emotional contact. The improvisation can imply composition of songs linked up with listening to recorded music by Hi-Fi or live music.

Within the musical improvisation the Author/Musictherapist works out the differentiation of the sound pitch and dynamic gradation.

- Method of Swelling or Culmination Method.

By means of a gradual increase in the modulation of the musical parameters (time, velocity, dynamics, rhythm and meter, intensity, duration and sound pitch) and the vocalization the Author/Musictherapist makes the patients achieve an 
emotional swelling/culmination and then the slackening.

- Formulation of three/five Protocols for each BERSVE and SEE administration.

These protocols show data with regard to:

- preparation of the musictherapist for the musictherapy session (tonic-muscular and emotional state, availability to welcome patients, empathy, bodily-sonorous-musical associations, etc.); - setting (characteristics of the environment in which the musictherapy session takes place: light, smells, temperature, sounds, noises, etc.; instrumental operating group: bodily-sonorous-musical instruments, cSMI, ncSMI, SSMI, ESMI; SRME, SEE, BERSVE production by the patientmusictherapist system); - conclusion of the musictherapy session (data as to the patientmusictherapist system: tonic-muscular state, postural and somatic attitudes, neurovegetative, motor and sensorial responses to bodily-sonorous-musical elements and silence intervals; parametral analysis of the sonorous-musical production and sonorous identity; analysis of the communication and relation dynamics; analysis of the symbolic elements that characterize the sonorous-musical production; sonorous interaction with the environmental noises and sonorous identity, and data processing of the environmental acoustic stress.

- Formulation of the patient's Somatic and Graphic Pattern (SOMPAT) [2].

The algorithm of the SOMPAT Index (it's "R"), in the tk time, (where $\mathrm{k}=1, \ldots, \mathrm{n}$ ) is:

$\mathrm{R}=\mathrm{f}[\mathrm{C}+\mathrm{Fm}(\omega, \beta, v)+\mathrm{ULM}(\alpha \mathrm{d}, \alpha \mathrm{s}, \mu \mathrm{d}, \mu \mathrm{s})+$ $\operatorname{LLM}(\gamma \mathrm{d}, \gamma \mathrm{s})]$.

$\mathrm{R}$ is function (f) of: - the vocal discharge $(\mathrm{C})$; the facial mimic (FM), that is joint in the eye $(\omega)$ and mouth $(\beta)$ and face (v) dynamism; - the motricity of the upper limbs (ULM), where $\alpha \mathrm{d}$ and $\alpha$ s are right and left limbs; $\mu \mathrm{d}$ and $\mu \mathrm{s}$ are right and left hands; - the motricity of the lower limbs (LLM), where $\gamma d$ and $\gamma \mathrm{s}$ are legs and feet of the right and left limbs.

For C, FM, ULM and LLM, the values are in the range $0-2$.

For $\mathrm{R}=\mathrm{f}$ [C, FM, ULM, LLM], the scale of the values is in the range $0-8$.

- Administration of Patient-Environment - Music Index (PEMI) at time $t_{0}$ and $t_{n}$, in order to estimate the patient's behaviour evolution and the Musictherapeutic Advancement Index (MAI). [1] Moreover the Musictherapeutical Advancement Index (MAI) is determined:

$\operatorname{MAI}\left(\mathrm{t}_{\mathrm{n}}\right)=\left[\operatorname{PEMI}\left(\mathrm{t}_{\mathrm{n}}\right)-\operatorname{PEMI}\left(\mathrm{t}_{0}\right)\right] / \operatorname{PEMI}\left(\mathrm{t}_{0}\right)$.

The test score is from 0 to 100 , in order to set up the patient's Recovery Advancement Index (RAIn).

In order to define with a logical and mathematical index the relation evolution of patient- environment-music system by musictherapy treatment, this methodology includes two Dimensional Categories (OME-MLMP): - 1) Social and Environmental Dimensional Category (OME), with three sub-units: Oneself (O); Man (M); Environment (E).

- 2) Music Dimensional Category $\left(\mathrm{M}_{\mathrm{l}} \mathrm{Mp}\right)$, with two sub-units: Music listening $\left(\mathrm{M}_{1}\right)$; Music made by the musictherapist and/or the patient (Mp).

Therefore, the Authors set up a Relation Evaluation Scale (RES), with five behaviour systems: Closing (C), Exploration (E), Expression $(\mathrm{X})$, Interaction (Y), Integration (W).

These systems (CEXYW) are valued in connection with the musical parameters of Intensity (J), Duration (D), Rhythm ( R ).

The RES is planned with a scansion of the parameters from 0 to 100, and a gap of 20 units.

The Authors define the five behaviour systems in this way:

- Closing is a patient's behaviour addressed to himself, other people, environment, music and musical instruments that are in the musictherapeutic setting;

Exploration shows a sensory interest of the patient in the five elements $\left(\mathrm{OME}-\mathrm{M}_{\mathrm{l}} \mathrm{Mp}\right)$ of the two Dimensional Categories;

- There is the Expression when the patient shows an expressive attitude to other people and to the environment with music made by himself too;

- There is the Interaction if the patient accepts the presence and the dialogue of other people or of the elements of the music or of the environment;

Integration is the evolutive aim of the therapist-patient system and the last stage of the musictherapeutic treatment.

By a suitable algorhythm the CEXYW system and the JDR parameters can be put in correlation with the five elements $\left(\mathrm{OME}-\mathrm{M}_{1} \mathrm{Mp}\right)$ of the two Dimensional Categories.

The Authors have carried out the research presented in this scientific work in the spaces A1 and GrZ1.

The teamwork is made by a musictherapist / pedagogist, a sound / landscapist / gardentherapist.

The patients are set in three groups: PG1: children; PG2: young / adult people; PG3: old people.

The patients of the three groups (PG1, PG2, PG3) are eighteen: six people within each group.

Therefore, the Authors set up the matrix [PG $(3 ; 6)]$.

There are weekly-sessions (55') for six months.

A Questionnaire $(\mathrm{Q})$ is administrated at $\mathrm{t}_{0}$ time, during the treatment (every two months) and at $t_{n}$ time at the end of the treatment. 


\subsection{Structure of the Phases}

3.3.1. Analysis. There are three methodological phases that have the temporal structure F1, F2 and F3.

- Structure of F1 Phase.

- Musictherapy treatments (MTF1) for each group PG $(1,2,3)$ in $\Delta \mathrm{t}_{\mathrm{k}}$ time (where $\left.\mathrm{k}=1,2, \ldots, \mathrm{n}\right)$ in the indoor environment (A1).

- Questionnaire (QA1) for each patient (ten items / liking-indices) at $t_{0}$ time and at $t_{n}$ time.

- Assessment scale (S) of Q with the structure: [S: 0-10] gap-range.

At the end of the F1 phase the therapeutic behavioural responses of each patient are monitored and set down in the matrix $\left\{\mu_{1}[(\mathrm{~A} 1)],[\mathrm{Q}(\mathrm{A} 1)]\right\}$.

-Structure of F2 Phase.

- MTF2 for PG $(1,2,3)$ in $\Delta t_{k}$ time (where $\mathrm{k}=1$, $2, \ldots, \mathrm{n})$ inside the Green Zone 7 (GrZ7).

- Questionnaire QGrZ7 (with reference to GrZ7) for each patient $\mathrm{PG}(1,2,3)$.

Moreover, at the end of the F2 Phase the therapeutic behavioural responses of each patient are monitored and set down in the matrix $\left\{\mu_{2}[(\mathrm{GrZ7})],[\mathrm{Q}(\mathrm{GrZ7})]\right\}$.

The musictherapy treatments are proposed in different cycles inside the F1 and the F2 Phases.

The methodology of the MusGar-EnEdExPe is articulated by an interconnected structure too in order to get a further therapeutic advancement founded on the contribution of some seminars as regards the environmental education joined to the methods of the experimental pedagogy.

The integrated rehabilitation process is individualized in relation to the features and the pathologies of the patients.

The environmental education is articulated according to some moduli of information, professional training and practical activities involving the plant-growing and multisensorial stimuli.

The environmental education is carried out by study seminars with regard to the Culture of the Communication, Environmental Education and Musictherapy.

Through these study seminars it is possible to acquaint the people with the importance of integrated methodologies in order to achieve multifunctional therapeutic results.

The environmental education is carried out as to the structure of the plants and their benefits and the plant sowing that the patients can bring into effects.

Afterwards they can cultivate these plants inside some spaces/greenhouse that are settled close to the A1, A2, A3 spaces.
The environmental education is due to provide people with the culture of the landscape, ecosystems and protection of biodiversity.

The forest ecosystems are made up of environmental factors that give prominence to colourful landscapes.

The wealth of nature and forest biodiversity and landscapes offers an extraordinary presence of formations of plants and wildlife [18].

These elements and the meteorological and climatic peculiarities, the features of the soil and terrain and the topography promote the distribution of the species.

All over the world the coasts are illuminated by multiform highlights and are scattered like diamonds alternating between sea and land.

Ancient fortifications, coastal towers, rocky shores and variety of territorial morphology give rise to an extraordinary biological diversity of marine and terrestrial ecosystems that are unique.

This exceptional uniqueness deserves a careful conservation [17].

Plans of the activities of environmental education are fundamental elements in order to carry out an integrated design of Environmental Culture [22].

\section{Results}

The results of the matrix $\left\{\mu_{1}[(\mathrm{~A} 1)],[\mathrm{Q}(\mathrm{A} 1)]\right\}$ and the matrix $\left\{\mu_{2}[(\mathrm{GrZ7})],[\mathrm{Q}(\mathrm{GrZ7})]\right\}$ are set down in a system by tables and graphs in relation to $\mathrm{A} 1$ and GrZ7 during the temporal structure $t_{0}-t_{n}$ time.

In the F3 Phase the results are set down in the final matrix $\left\{\mu_{3}[(\mathrm{~A} 1),(\mathrm{GrZ7})],[\mathrm{Q}(\mathrm{A} 1),(\mathrm{GrZ7})]\right\}$.

For each patient the Authors analyse the PSMA, the FSMA, the MAD, the SOMPAT, the PEMI, the MAI, the RAIn, and set down the final system comparing the results:

$\left\{\operatorname{MT}_{\mathrm{k}}\left(\Delta \mathrm{t}_{\mathrm{k}}\right) ;(\mathrm{A} 1)\right\}$ and $\left\{\mathrm{MT}_{\mathrm{k}}\left(\Delta \mathrm{t}_{\mathrm{k}}\right) ;(\mathrm{GrZ7})\right\}$.

The secretions of the peptide hormones endorphins and the endogenous opioids enkephalins increase and bring a state of patient's tranquillity and a better mood.

The patients $(91 \%)$ show the musictherapy joined to the environmental education and the gardentherapy inside the Green Zones and the ecosystems meets with their approval.

After the musictherapy treatment the pedagogist facilitates the group narration process.

By means of this integrated and multifunctional methodology the patients show emotions that stimulate an increase in the creative energies and dynamisms.

In this way it is possible to reduce the patient's stress and every trauma can be processed [6]. 
The emotions are instantaneous and partly neurovegetative and partly culturally acquired responses to a perception (proprioception, interoception, exteroception, background feelings) and contribute to set up the human evolutionary kit and perform adaptive and fundamental functions for the life.

The emotion can be defined as a fairly intense inner process linked up with psychic and physiological reactions.

The emotions are action plans with which the evolution has endowed us to manage life's emergencies.

The etymology of the emotion (word) takes root to the Latin verb moveo, "to move", with the additional prefix "e-" ("movement from"), to denote that a tendency to act joins in every emotion.

The emotions are transcultural - in relation to the fundamental traits - as well as absolutely characterized by subjectivity.

The hedonic value (or affective tone) characterizes the emotions: positive hedonic value for some emotions (joy, enthusiasm, etc.), negative hedonic value for other emotions (anxiety, sadness, etc.).

Neuropsychological evidences show that the emotional state, both positive and negative, can give rise to activation (high arousal) or deactivation (low arousal).

Therefore, positive emotional states can show low arousal (calm, etc.) or high arousal (happiness, etc.), negative emotional states can show low arousal (sadness, depression, etc.) or high arousal (anger, fear, etc.).

Three (main) functions are performed by the emotions: action, that predisposes to react to an emergency, communication and reflection, that allow you to communicate with yourself and with the others, exploring needs and objectives.

Furthermore, the emotions can facilitate the creative thinking.

The link between creativity and emotional state is very complex and seems to be regulated by the interaction among hedonic value, emotional activation and motivation.

Neuroimaging experiments show that we use the same neural systems to perceive our body, social relationships, our moral judgments and creative inspiration.

A good mood positively affects perception processes and contributes to broaden the outlook on life.

The analysis of complex interactions shows that positive emotional states are a better source of creativity than negative ones.
However, the level of activation, or arousal, also plays a role: if this variable is introduced, it's possible to realize that the positive activating states promote creativity, flexibility and cognitive functions most and therefore high levels of inventive originality.

As far as low arousal negative emotions are concerned, some authors think these emotions have no connection with an increase in creativity, while high arousal negative emotions would be negatively correlated, above all because they reduce the cognitive flexibility.

Some recent studies show that the negative emotions do not stifle the creativity but can shoot a "spark" to switch on the creativity.

Moreover, the negative emotions can stimulate the people to stay focused for longer within the brainstorming sessions.

Often the days characterized by a greater creative production turned out to be those that started with negative emotions and then ended in a positive way.

\section{Conclusions}

It is important to consider the symbolism, the rituals and the myths and the mythologies of the patient's culture or group work.

The immigrants are increasing and they need to recreate their fractured identity using music, integrating past and present experiences.

At the same time the women are over represented among the group people suffering from long-term illness. [8].

To give significance to the life is a prerequisite to the health [12].

The MusGar-EnEdExPe must perceive and grasp the contextual, symbolic and functional meanings of the music that the patient brings from his culture, in order to strengthen his identity and sense of social belonging.

The MusGar-EnEdExPe promotes the patient's psychophysical activation, better mood/affectivetone and relationships and contributes significantly to improve the life quality.

The defence of the forest ecosystems, protected natural areas and national and regional natural parks must be integrated with Management Plans, Landscape Plans and Fire Prevention Plans related to: - the planning of the development and valorization of natural resources, coastal zones, limpid sea-water and chains of mountains and woods; - the preservation of the high quality standard of the forest environment and the scenography of the vegetation, necessary for the people to achieve social, cultural and spiritual benefits that are joined in the improvement of landscape and territory and 
particularly of woods and forests, the active maintenance of the productive biosphere, the economic, psychological, recreational, educational and cultural resources of the ecotourism [16].

The enhancement of the landscape contributes to the development of the culture. Therefore, public administrations and authorities promote and support special and opportune activities of knowledge, information, professional training, qualification, valorization and enjoyment in relation to the landscape [18].

The activities of enhancement and valorization of the landscape are implemented with all due respect towards the protection needs [19].

The activities of States, regions, local governments, as well as all persons that carry on public functions and operate on the national territory, must be respectful of the principles of conscious land use, protection and preservation of the landscape features, achievement and production of new integrated and coherent landscape values, in accordance with criteria of sustainable quality.

The improvement of the life quality is the fundamental and final objective.

\section{References}

[1] De Serio, A. and Forenza, D. (2002) 'Indice d'Interazione Ambientale-Musicale (IPAM)', in Di Pinto L. (ed.) Metamorfosi e Musica in Fenomenologia, G. Laterza, Bari, pp. 240-245.

[2] De Serio, A. and Forenza, D. (2004) 'Musictherapy and Interaction with Patient/Environment: a new Methodology', in Proceedings of the $2^{\text {nd }}$ Regional Mediterranean Conference, Hellenic Association of Group Analysis and Psychoterapy, Atene, p. 50.

[3] De Serio, A., Forenza, D. and Megna, G. (2006) 'Posttraumatic disabilities and Musictherapeutic support', in Proceedings of the $15^{\text {th }}$ European Congress ESPRM, Madrid, pp. 460-461

[4] De Serio, A. and oth. (2011) 'I valori aggiunti nel trattamento recuperativo: osservazione longitudinale sulle favorevoli ricadute della musicoterapia in acqua e a secco in gruppi di pazienti', in Proceedings of the 39th SIMFER National Congress, Reggio Calabria, p. 451.

[5] De Serio, A. and Forenza, D. (2012) "Observation about a musictherapy treatment for a group of patients in vegetative state", Italian Journal of Rehabilitative Medicine, MR: 26 (1 to n. 2-3), Minerva Medica, Torino (Italy), 2012, pp. 22-24.

[6] De Serio, A. and Forenza, D. (2013) 'Musicoterapia integrata con onoterapia e gardenterapia nella riabilitazione in età evolutiva: contributo preliminare', in Proceedings of the 13th National Congress, SIRN, Bari (Italy), pp. 420421.

[7] De Serio, A. (2014) 'Edible rs/musical instruments for geriatric disabled and wheelchair/bound patients', in Proceedings of $14^{\text {th }}$ World Congress of Musictherapy, IMC University of Krems, R. \& W. Smutny OEG, Vienna, p. 423.

[8] De Serio, A. (2015) 'A Group-Music-Therapy Plan for Family Members of People with Disabilities', in Proceedings of IAGP $19^{\text {th }}$ International Congress, Rovinj (Croatia), p. 82

[9] De Serio, A. and Forenza, D. (2015) 'A new method of Group Musictherapy/Gardentherapy for not-mentally retarded wheelchair-bound patients', in Proceedings of IAGP $19^{\text {th }}$ International Congress Proceedings, Rovinj (Croatia), p. 94.

[10] De Serio, A. (2015) 'Strumenti Sonoro-Musicali Commestibili in Musicoterapia per i disturbi alimentari in età evolutiva', in Proceedings of the National Congress on Il gusto delle artiterapie. Assaggi per nutrire il corpo e l'anima - I disturbi alimentari e arteterapia: rete tra ospedale e territorio, San Paolo Hospital, Infantile Neuropsychiatry, University, Milan, pp. 25-30.

[11] De Serio, A. (2015) 'Cibo, musica e strumenti sonoromusicali commestibili', in Proceedings of the National Congress on Il Gusto delle Arti Terapie, SPID, Art Therapy It., APID, AIM, Artiterapie-Sineresi Center, EXPO 2015, Milan, pp. 13-20.

[12] De Serio, A. (2015) 'Musictherapy and the neoplastic diseases', in Proceedings of the 8th Nordic Musictherapy Congress, NTMC, Oslo, p. 80.

[13] De Serio, A. and Forenza, D. (2015) 'Environmental Education and Ethics for the Pedagogy of the Redevelopment and Enhancement of the Landscape', in Proceedings of the World Congress on Education, WCE 2015, Dublin (Ireland).

[14] Imberty M. (1979), Entendre la musique, Dunod, Paris, 1979.

[15] De Serio A. (2009) Musictherapy in the young people rehabilitation from disorders of mental development', in Proceedings of the 7th International Arts Therapies Conference, Riga Stradina University, Cesis (Latvia), 2009 July 17-19, pp. 85-86.

[16] Forenza, D. and Tortorici, G. (2013) 'L'importanza dell'Educazione Ambientale nella Pianificazione paesaggistica e nella Tutela della Biodiversità', in proceedings of 9th National Congress on Biodiversità Territorio, Paesaggio e Servizi Eco-sistemici, Ed. CIHEAM-IAMB, Valenzano (BA), Italy, Vol 3º, pp. 358363.

[17] Forenza, D. (2015) 'Rilevanza dell'educazione ambientale nella pianificazione paesaggistica della 
forestazione urbana e nella Tutela della Biodiversità', in Proceedings of 10th National Congress on Biodiversity (Ed. Alba E, Benedetti A, Bucci G, Ciaccia C, Pacucci C, Pinzari F, Scarascia Mugnozza G.), CNR, Roma (Italy), 35 sept 2014, pp. 278-285.

[18] Forenza, D., (2016) 'Valenze poliedriche della Biodiversità, Paesaggio e Valorizzazione del territorio', in Proceedings of 11th National Congress on Biodiversity, Matera, 2016, ISBN 9788894133226, p. 230.

[19] Forenza, D., De Serio A. and Di Marzo M. (2016) 'Educazione e Comunicazione Ambientale per la Cultura della protezione del paesaggio', in Proceedings of 11th National Congress on Biodiversity, Matera, 2016, ISBN 9788894133226, p. 236.

[20] Forenza, D. and Calderazzi, A. (2016) Linee metodologiche per la riqualificazione del paesaggio urbano e rurale', in Proceedings of 11th National Congress on Biodiversity, Matera, 2016, ISBN 9788894133226, p. 263.

[21] Forenza, D. and Di Marzo, M. (2016) Valorizzazione del paesaggio: un approccio integrato per il territorio, in Proceedings of 11th National Congress on Biodiversity, Matera, 2016, ISBN 9788894133226, p. 265.

[22] De Serio A. and Forenza D. (2016) "Environmental Ethics and Pedagogy for the landscape Redevelopment", International Journal for Infonomics /IJI), Vol. 9, issue 2, June 2016, Ireland, pp. 1152-1155. 